\title{
Impactos do Novo Corona Vírus sobre o mercado da Construção Civil
}

\author{
Impacts of the New Corona Virus on the Civil Construction market
}

Thaiza Maria Nascimento Pedro ${ }^{\dagger *}$, Barbara Braga Barbosa

Como citar esse artigo. Pedro, T.M.N; Barbosa, B.B. Impactos do Novo Corona Vírus sobre o mercado da Construção Civil. Revista Teccen. 2021 Jan./Jun.; 14 (1): 33-39.

\begin{abstract}
Resumo
A pandemia de Covid-19 surgiu em 2019, com o aparecimento de um novo vírus, com disseminação rápida e que já causou inúmeras perdas. A alta taxa de casos e de mortalidades é preocupante, levando diversos governos a estabelecerem medidas para sua contenção. Porém, essas medidas causaram consequentes impactos econômicos, pela paralisação de atividades produtivas, fato que não foi diferente na construção civil. Tendo isso em mente, o presente trabalho buscou realizar um estudo sobre o panorama atual desse setor, em um cenário após o início da pandemia, bem como apontar possíveis medidas para recuperação e tendências para o futuro. Foi observado que houve uma grande queda no capital geral e muitas demissões, sendo o setor informal o mais afetado. Todavia, também se observa uma pequena recuperação, baseada no aquecimento do mercado imobiliário e de medidas tomadas pelas construtoras, como ações de responsabilidade social, digitalização dos serviços e aplicação de novos métodos, que se apresentam como principais ações de retomada. Ademais, se destaca o uso das plataformas digitais como forma de divulgação e aproximação com os clientes, além da fundamental aplicação das medidas de prevenção da doença. Conclui-se que ainda há muito desafios, mas ainda que a crise da pandemia tenha causado prejuízos, pode representar uma oportunidade de crescimento.
\end{abstract}

Palavras-chave: : Construção civil; impactos econômicos; pandemia; Covid-19; coronavírus.

\section{Introdução}

Os anos de 2019 e 2020 ficarão marcados pela disseminação de um novo vírus, o Covid-19 pelo mundo, causando a perda de inúmeras vidas. Para conter os avanços da doença, foram tomadas medidas de distanciamento social em diversos países, fator que tem provocado efeitos recessivos sobre a economia mundial com prazo ainda indeterminado. Além disso, causou rápidas mudanças no mercado de trabalho, principalmente entre as pessoas que vivem na informalidade.

Não é diferente no setor da construção civil. De acordo com o SEBRAE (2020a), no Brasil, muitos governos estaduais determinaram o fechamento de serviços essenciais, como os da construção civil, com impactos ao setor de serviços que representa mais de $75 \%$ do PIB brasileiro. Nesse sentido, serviços de alvenaria, elétricos e hidráulicos que dependem de contato físico estão enfrentando uma redução drástica da demanda.

Diante dessa temática atual, desenvolvemse questões problematizadoras: quais os principais impactos econômicos provocados pela pandemia do Covid-19? Quais desses impactos merecem destaque no setor da construção civil? Quais são as perspectivas para

\footnotetext{
Afiliação dos autores:

† Graduanda em Engenharia Civil, Universidade de Vassouras, Vassouras-RJ, Brasil.

${ }^{\ddagger}$ Docente do Curso de Engenharia Civil, Universidade de Vassouras, Vassouras-RJ, Brasil.
}

* Email de correspondência: mariathaizanascimento@gmail.com 
o futuro? Que medidas podem ser tomadas de forma corretiva para manutenção econômica do setor?

Dessa forma, o presente estudo visou realizar a síntese do panorama econômico da construção civil após a ocorrência da pandemia do novo corona vírus, destacando as principais repercussões na atividade da categoria. Para isso, levantaram-se os seguintes objetivos específicos: apontar os principais dados de impactos econômicos pós-pandemia; descrever as consequências econômicas para a construção civil; citar possíveis medidas de controle para a situação atual.

\section{Impactos econômicos do Novo Corona vírus $\mathrm{O}$ vírus da Covid-19}

Inicialmente, foi detectado como causador de um conjunto de casos de pneumonia em Wuhan, uma cidade da China, com uma rápida disseminação por todo o país. Posteriormente, houve um número crescente de casos em outros países do mundo, sendo em fevereiro de 2020 designado pela Organização Mundial da Saúde a doença COVID-19, que significa doença do coronavírus 2019. $\mathrm{O}$ vírus causador da doença é designado por coronavírus 2 da síndrome respiratória aguda grave (SARS-CoV-2) (MCINTOSH, 2020).

$\mathrm{Na}$ microscopia eletrônica, estes vírus são vistos como círculos, com espículas que terminam em pequenas gotas que se exteriorizam de sua superfície, parecendo uma coroa. Esse fator designa seu nome, já que "corona" em latim tem o significado de coroa (SÁFADI, 2020).

Os coronavírus são responsáveis por infecções respiratórias e intestinais em humanos e animais. No ser humano, a maioria das infecções são causadas por espécies de baixa patogenicidade, levando a sintomas semelhantes aos de um resfriado comum. Eventualmente, podem levar a infecções graves em grupos de riscos, idosos e crianças (BRASIL, 2020a).

Entretanto, pandemias anteriores, causadas pelo SARS-CoV em 2002 e o MERS-CoV em 2012, atingiram mais de 10 mil pessoas, com taxas de mortalidade de $10 \%$ a $37 \%$ respectivamente (BRASIL, 2020b).

Conforme o site da Organização Pan-Americana da Saúde (2020), até o dia de 30 de novembro de 2020 o número de casos ao redor do mundo ultrapassava a marca de 60 milhões, com mais de 1,4 milhões de mortes (Figura 1).

De acordo com o site do Ministério da Saúde (BRASIL, 2020c), até o dia 30 de novembro 2020 havia mais de seis milhões de casos confirmados no Brasil, com mais de 170 mil óbitos. Na Tabela 1, podemos ver esses números conforme a Região, entretanto, esses

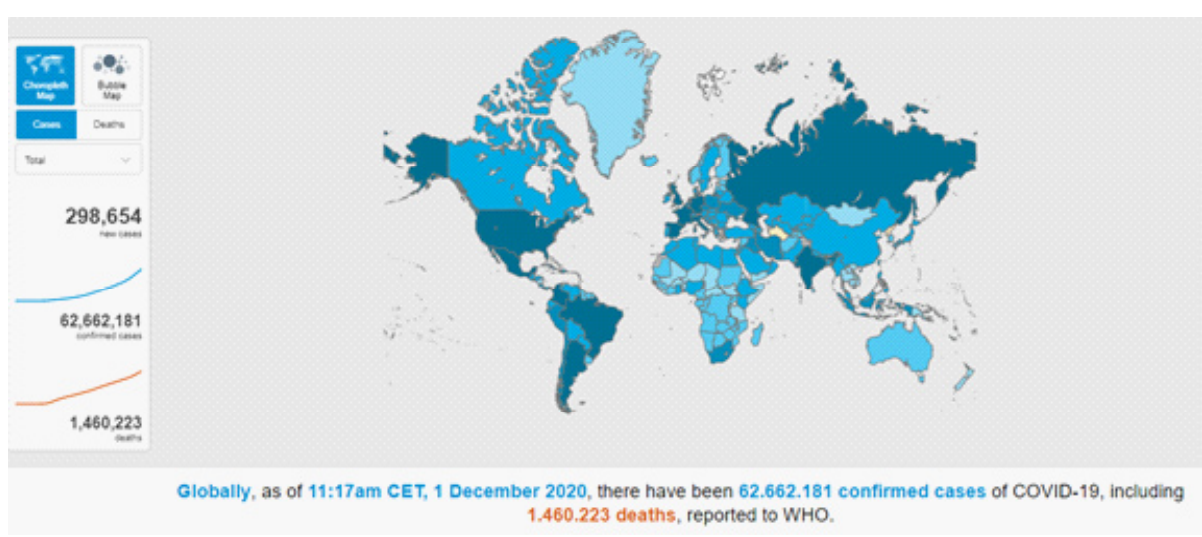

Figura 1. Casos de Covid-19 ao redor do mundo.

Fonte: Organização Mundial da Saúde (2020).

Tabela 1. Número de casos por região no Brasil.

\begin{tabular}{|c|c|c|c|}
\hline Região & População & Casos Acumulados & Óbitos Acumulados \\
\hline Total & 210.147 .125 & 6.335 .878 & 173.120 \\
\hline Sul & 29.975 .984 & 966.486 & 16.729 \\
\hline Sudeste & 88.371 .433 & 2.202 .213 & 78.998 \\
\hline Nordeste & 57.071 .654 & 1.631 .796 & 44.467 \\
\hline Norte & 18.430 .980 & 769.630 & 16.791 \\
\hline Centro-Oeste & 16.297 .074 & 765.753 & 16.135 \\
\hline
\end{tabular}


números são atualizados constantemente.

O crescimento dos casos ocorreu de forma exponencial por todos os continentes em menos de um ano de identificação do novo vírus (Figura 2). Nesse sentido, houve a superlotação de hospitais, dificultando ainda mais o tratamento e aumentando os casos de morte.

Em concordância, a Fundação Oswaldo Cruz Fiocruz (2020) afirma:

O coronavírus se dissemina rápido, o que pode significar muitos casos com hospitalização num curto espaço de tempo. Isso sobrecarrega o sistema de saúde e pode gerar grandes impactos sociais e econômicos. Por isso, é fundamental entender como o vírus é transmitido e prevenir que o mesmo se espalhe. (...) A transmissão dos coronavírus se dá de pessoa para pessoa: pelo ar ou por contato pessoal com secreções contaminadas (gotículas de saliva, espirro, tosse, catarro).O ciclo pode se iniciar com contato pessoal próximo (toque ou aperto de mão) ou contato com objetos ou superfícies contaminadas, seguido de contato com a boca, nariz ou olhos (FIOCRUZ, 2020)

Dessa forma, as ações de enfrentamento ao Covid-19 envolvem o distanciamento social, evitando aglomerações e contato físico entre as pessoas. É recomendado a lavagem frequente das mãos e o uso do álcool em gel como antisséptica, assim como o uso da máscara, descartável ou caseira. O monitoramento é feito pela temperatura e apresentação de sintomas gripais (CARVALHO; NINOMIYA; SHIOMATSU, 2020).

As medidas de bloqueio total ou parcial realizada por vários países levaram a diminuição das atividades econômicas, com reflexos em todos os setores.

\section{Repercussões econômicas mundiais e nacionais}

Conforme a Confederação Nacional de Serviços (2020), considerando a alta transmissibilidade do coronavírus e a projeção de um número elevado de mortes, os governos de diversos países adotaram medidas extremas, com rigorosas restrições à mobilidade das pessoas e fechamento temporário de empresas. Essas medidas, que foram vistas como as únicas possibilidades preventivas, causaram impactos severos nas economias (CON).

De acordo com Silva e Silva (2020), o momento econômico pós-pandemia da Covid-19 pode representar uma recessão econômica mais profunda do que a crise mundial de 2008-2009 e a crise da dívida da América Latina dos anos 1980.

Amitrano, Magalhães e Silva (2020) estima que cada mês de interrupção das atividades econômicas essenciais na Europa representa uma queda anual do Produto Interno Bruto (PIB) destes países em cerca de $3 \%$. A taxa de crescimento do PIB das economias avançadas deve ficar em torno de $-6,1 \%$, a dos países em desenvolvimento em $-1,0 \%$ e a da economia mundial em $-3 \%$. Os impactos serão mais intensos na demanda por bens e serviços do que na oferta de bens e serviços.

A Figura 3 apresenta o impacto potencial sobre o PIB das paralisações parciais ou completas em alguns

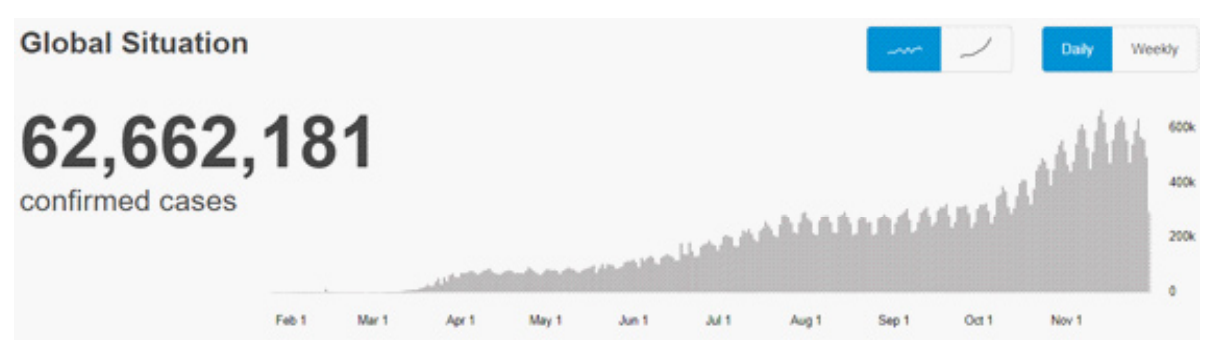

Figura 2. Crescimento exponencial de casos de Covid-19 ao redor do mundo.

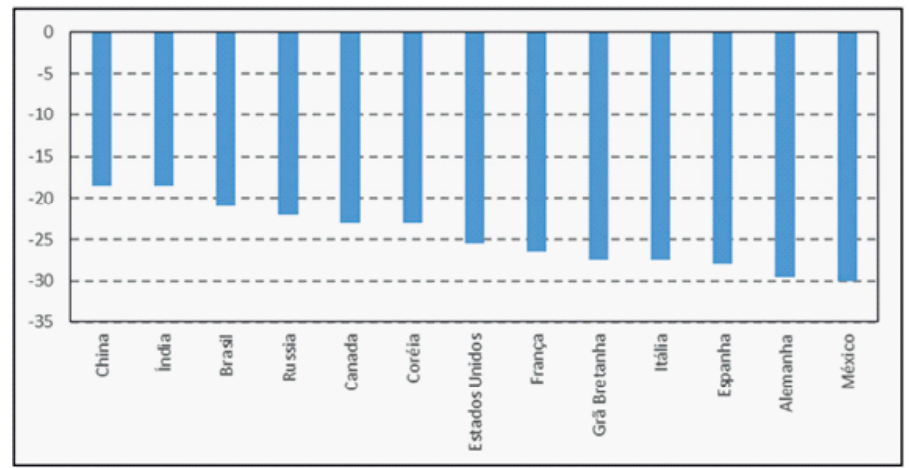

Figura 3. Impacto potencial inicial sobre o PIB em \%. 
países selecionados, em \% do PIB a preços constantes.

Essa crise possui uma característica particular, pois afeta ao mesmo tempo a oferta e a demanda. $\mathrm{O}$ isolamento social, a ruptura nas redes globais de suprimento e o protecionismo comercial de alguns países reduzem a capacidade de produção e o abastecimento dos mercados. O aumento do desemprego, as incertezas quanto ao futuro e a redução no crescimento global limitam o consumo, o investimento e as exportações. Cabe somente ao Estado atuar de maneira contracíclica, porém anos de desmonte no setor público e privatizações restringem os instrumentos necessários para tal ação (RODRIGUES, 2020).

Conforme Bosquerolli et al. (2020), na economia brasileira, os setores da indústria, comércio e serviços apresentaram em março queda de $9,1 \%, 2,5 \%$ e $6,9 \%$ respectivamente. A indústria teve aumento de produção de alguns produtos devido à quarentena, como papel higiênico, absorventes, fraldas, desodorantes, sabões, detergentes, xampus, seringas, agulhas, luvas de borracha, artefatos de proteção e caixões. No entanto, isoladamente estes não têm força para levar todo o setor a um crescimento.

O cenário econômico do Brasil era de superação da crise de 2014/2017, a qual foi originada por uma combinação de choques de oferta e demanda, devido a erros de política econômica. Estes fatores provocaram uma redução do crescimento da economia brasileira e incerteza sobre a solvência das finanças públicas. Contudo, as medidas de contenção dos gastos públicos, a partir de reformas, e de flexibilização da política monetária, estavam mostrando sinais de recuperação econômica no longo prazo. Essa trajetória foi interrompida a partir da chegada do vírus no país (SILVA; SILVA, 2020, p. 2).

Inúmeras projeções têm sido feitas, considerando cenários mais otimistas e pessimistas, com quedas do PIB brasileiro entre 3 e 10\%. A Figura 4 apresenta a variação do PIB real nos últimos sete anos, após o último ano de crescimento econômico, e a projeção para o ano de 2020, considerando um cenário mais otimista

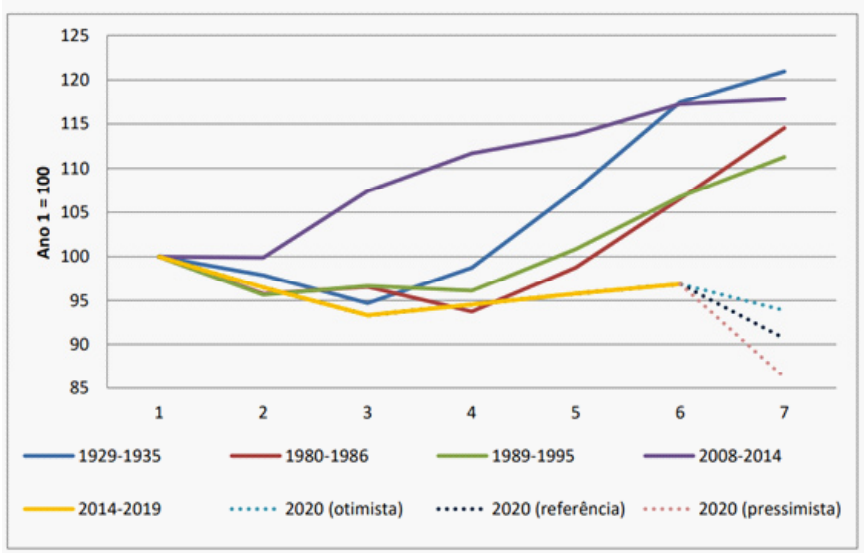

Figura 4. Variação do PIB real nos 7 anos após o último ano de crescimento.

Fonte: Rodrigues (2020, p. 9). e um pessimista.

O Ministério da Economia (BRASIL, 2020d) estima que o impacto a curto prazo da quarentena é de R \$ 20 bilhões. Em longo prazo, os custos envolvidos no isolamento devem ser muito maiores, pois quanto mais tempo em regime de isolamento social maior será a perda de arrecadação das empresas e maior o endividamento, promovendo um número crescente de falências e destruição de postos de trabalho.

\section{A Covid-19 e o mercado da Construção Civil Panorama do mercado da Construção Civil pós- pandemia}

O cenário do mercado da construção civil demonstrava que o setor será um dos mais afetados. Conforme Rodrigues (2020), tomando apenas os resultados para o Brasil no cenário de referência, percebe-se que em termos de valor adicionado o setor com maiores perdas é o de construção civil $(-16,1 \%)$, seguido pela indústria extrativa $(-13,9 \%)$. A queda do valor adicionado no setor responde por aproximadamente $10 \%$ do total, a redução de suas ocupações corresponde a $15 \%$ de toda retração no país. A queda mais que proporcional das ocupações nesse setor em relação ao valor adicionado relaciona-se com o elevado grau de informalidade em ambos.

A Internacional de Trabalhadores da Construção e da Madeira (2020) afirma que ainda que os trabalhadores do setor da construção não sejam os mais expostos ao ambiente da doença, como os profissionais da Saúde, a variável de proximidade física se assemelha ao deste último. A possibilidade de contração da doença entre os trabalhadores da construção civil é superior a $50 \%$, chegando a $71 \%$ para assentadores de canalização (edificações).

De acordo com a Confederação Nacional de Serviços (2020), o PIB da construção civil brasileira poderia cair $8,3 \%$ com a paralisação das obras por um período de 60 a 90 dias. O ajuste sobre a mão de obra para acomodar essa redução e atividades poderia alcançar 637 mil postos de trabalho.

Conforme Martins (2020), o setor da construção civil, após uma grande queda, vinha sendo retomado, e no início do ano, havia projeções para crescimento, com um alto índice de confiança dos empresários. Porém após a pandemia o início da pandemia, com a paralisação das obras e de toda a cadeia de suprimentos, toda a recuperação foi engolida pela crise.

A Câmara Brasileira da Indústria da Construção - CBIC (2020a) afirma que nos três primeiros meses do ano, a construção civil registrou uma queda de $2,4 \%$ na sua produção e perda de cerca de 440 mil ocupações. Os mais afetados foram os microempreendedores informais, que realizam principalmente pequenas obras de reformas. 
Entretanto, de acordo com Fontes (2020) relata que apesar das expectativas para o segmento no início da pandemia, o setor, além de sofrer menos do que o esperado, conseguiu se recuperar rapidamente. Dados demonstram que o mês de junho foi o melhor para a indústria no Brasil em quatro anos.Inicialmente, nos meses de março, abril e maio, houve um saldo negativo no estoque de empregos formais, mas em junho, o setor recuperou os postos de trabalho e teve saldo positivo, com 17.270 novas vagas.

Adicionalmente, a Figura 5 mostra a série histórica de confiança no setor, onde é possível ver um aumento, após a queda brusca no início da quarentena. Conforme Martins (2020), esse representa o melhor momento para estruturar novas estratégias no setor.

\section{Série histórica}

Indice (0 a 100 pontos)*

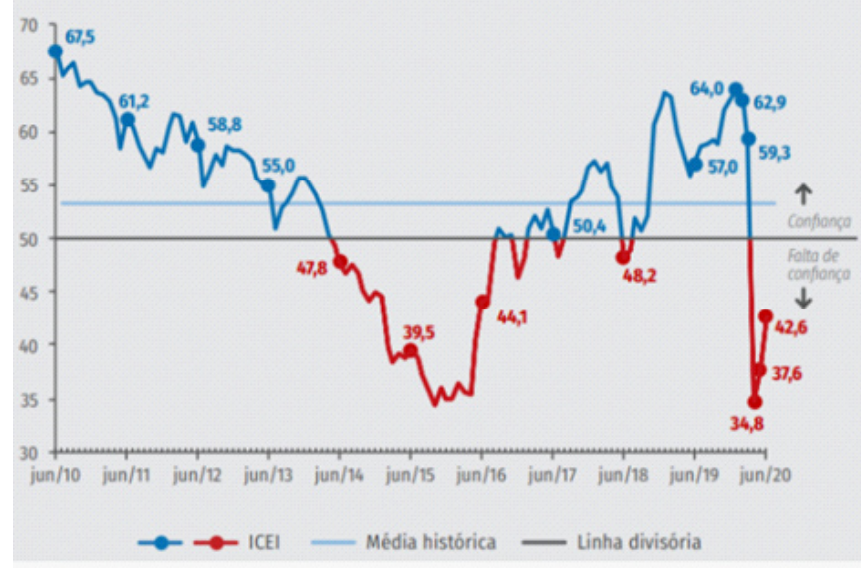

Figura 5. Série histórica do índice de confiança na construção civil 2010-2020.

Fonte: Martins (2020).

O que explica essa situação foi a adoção de um conjunto de medidas que deu apoio às construtoras, fazendo com que as empresas mantivessem suas operações e cumprissem os cronogramas das obras. Além disso, as construtoras investiram em vendas online e visitas virtuais a imóveis. Porém, esse cenário de otimismo gera preocupações com o futuro, quando os impactos da crise a longo prazo se apresentarem. O investimento em obras de infraestrutura será fundamental (FONTES, 2020).

$\mathrm{O}$ retorno das atividades aconteceu com muitas limitações quelevaramaodesenvolvimentodeestratégias para superar os desafios. As construtoras realizaram atividades de suporte às comunidades, assumindo uma responsabilidade social, e desenvolveram novos métodos construtivos, mais rápidos e sustentáveis, que propiciaram a construção de hospitais para atender a alta demanda. Também houve uma aceleração em processos digitais, sendo possível obter vendas e averbação de imóveis de forma remota (MARTINS, 2020).

Outro fator que contribui foi o aquecimento do mercado imobiliário devido a um cenário de juros baixos, Selic e alternativas de investimento. Além disso, estabeleceu-se uma visão da casa própria como um refúgio de segurança (MATTOS, 2020).

Entretanto, conforme Camargo (2020), esse panorama não tem atingido o mercado informal da construção, que ainda sofre com os efeitos da pandemia. Nessa área 1,4 milhões de pessoas perderam seus trabalhos, representando uma baixa de 3\%.

Para a Bosquerolli et al. (2020) a recuperação nacional dependerá muito, da construção civil e da assistência social, pois possuem efeitos multiplicadores máximos quando a economia está em recessão. A construção civil possui sua importância ressaltada por ser um segmento que sustenta a demanda; aumenta a produtividade; induz o gasto e investimento privado; tem forte efeito multiplicador em diversos outros setores; a começar pela massa de salários; e tem um dos coeficientes de emprego mais altos da economia. $\mathrm{O}$ investimento na construção civil pode trazer crescimento econômico já em 2020, no entanto afirma que é preciso levar em conta os segmentos deste setor e suas potencialidades e limitações para o crescimento no curto prazo.

\section{Medidas e tendências para o futuro}

Primeiramente, é necessário se atentar para a importância das medidas de prevenção contra a disseminação do vírus. Essas medidas são fundamentais para a manutenção das atividades das construtoras, garantindo a segurança de seus funcionários.

Conforme a Câmara Brasileira da Indústria da Construção (2020b), algumas medidas são essenciais, como a higienização, de forma que a empresa deve possibilitar a lavagem frequente das mãos com o uso do álcool gel 70\%, limpeza e sanitização do ambiente de trabalho e ventilação cruzada, além de investir no uso de recursos tecnológicos para diminuir aglomerações.

Outra medida é manter os funcionários do grupo de risco em home office ou em férias remuneradas, bem como a adoção de turnos intercalados entre os demais funcionários. A todo o momento, devem ser disseminadas informações sobre a importância dessas medidas e sobre a Covid-19. No canteiro de obras, os profissionais devem utilizar Equipamentos de Proteção Individual - EPI, com redução de equipes numerosas e monitoração de sintomas entre os empregados, que em casos positivos, devem ser afastados (CÂMARA BRASILEIRA DA INDÚSTRIA DA CONSTRUÇÃO, 2020b).

Além disso, as medidas já citadas que foram tomadas por diversas empresas são aconselháveis, pois têm promovido a recuperação do mercado. Destacam-se 
as inovações nos métodos construtivos, a digitalização de processos e as ações de responsabilidade social.

Alguns casos de sucesso representam modelos que podem ser aplicados nas construções do futuro, como as obras de hospitais executadas de maneira mais rápida. O Hospital de Retaguarda de São José dos Campos é um bom exemplo, que de acordo com o site do G1 Vale do Paraíba e Região (2020), contou com investimentos de 12,9 milhões, divididos entre a prefeitura municipal e a iniciativa privada. $\mathrm{O}$ intuito era que o prédio fosse entregue em 45 dias e que a unidade permanecesse para atendimentos futuros na cidade, ao contrário dos hospitais de campanha.

Conforme o site da construtora Brasil ao Cubo (2020a), o hospital foiconstruído totalmente do zero e foi entregue em 36 dias, com 67 módulos e totalizando uma área de $1500 \mathrm{~m}^{2}$ (Figura 8). Na construção foram aplicados o método off-site (fora do terreno) com a acoplagem de várias seções com dimensões máximas de $15,00 \times 3,80 \times 3,90 \mathrm{~m}$ (comprimento $\times$ largura $\times$ altura), e o sistema Plug and Play BR3, método da empresa que permite o encaixe perfeito dos módulos os tornando semelhantes às construções tradicionais.

A empresa ainda é responsável do Hospital M'boi Mirim na cidade de São Paulo, com 48 módulos, 100 leitos e uma área construída de $1.350 \mathrm{~m}^{2}$, que foi entregue em 33 dias. O projeto arquitetônico contou com 25 engenheiros de diversas cidades e estados do país, trabalhando de forma totalmente remota, através de um modelo feito em Building Information Modeling - BIM, que permite o desenvolvimento interligado e inter-relacionado do edifício (BRASIL AO CUBO, 2020b).

A construção também foi modular e apresentou as seguintes vantagens e medidas aplicadas:

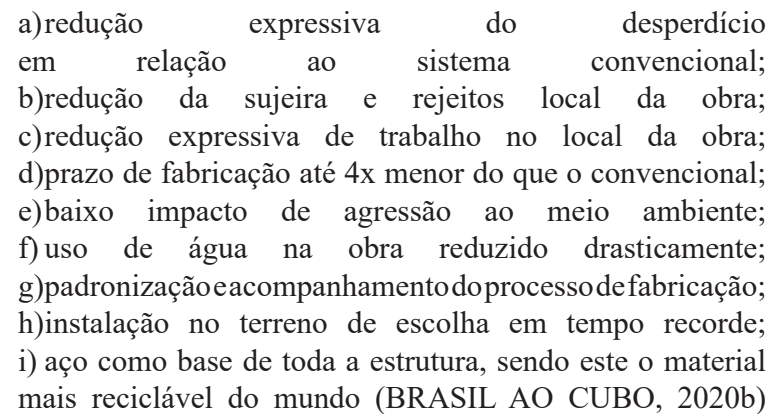

Para os microempreendedores e trabalhadores informais, é recomendado o uso dos canais digitais para divulgação dos serviços prestados e comunicação remota com os clientes. É necessário manter as informações sempre atualizadas, interagindo e entendo o seu público. Construções e reformas ainda têm sido realizadas, pelo aquecimento do mercado imobiliário e pelo fato de que, com o maior tempo em casa, há um aumento da procura por melhorias. Cabe aos profissionais divulgar seus serviços em ambientes que tem tido maior visualização, além de manter todos os cuidados para diminuir a propagação da Covid-19, para sua própria segurança e do consumidor. Esse também é outro aspecto que deve ser divulgado nas redes sociais (SEBRAE, 2020b).

Essas medidas são tendência para o setor, ao possibilitarem uma obra mais otimizada e que podem ser fundamentais para recuperação econômica. Representam a possibilidade de aplicação efetiva de técnicas já conhecidas, mas que ainda não eram muito disseminadas no Brasil, possibilitando avanços no setor. A aplicação de inovações tecnológicas na construção pode diminuir aspectos prejudiciais, como o alto índice de acidentes e impacto ambiental, trazendo um grande avanço para o setor.

\section{Considerações Finais}

A pandemia de Covid-19 representa um marco histórico, pela sua rápida disseminação e pelo seu grande impacto econômico. É fundamental seguir todas as medidas para prevenção e proteção contra as doenças, que envolvem lavagem frequente das mãos, uso de álcool em gel e máscara, eliminar aglomerações e manter o distanciamento social. Essa última causou a paralisação das empresas em diversos países, o que gerou quedas no Produto Interno Bruto e aumento do desemprego.

No setor da construção civil não foi diferente, sendo observada uma quebra abrupta no mercado, que vinha se recuperando de outras crises. Muitos postos de trabalhos foram prejudicados, com destaques para os pequenos empreendedores informais, que representam uma grande parcela da construção brasileira.

Entretanto, já se vislumbra uma saída, já que medidas tomadas pelas construtoras têm causado uma retomada econômica. Nesse sentido, se destacam a aplicação de novas técnicas que diminuam o tempo de obra e a tornem mais limpa e sustentável, com a diminuição de trabalhadores nos canteiros de obra. Além disso, temos as plataformas de trabalho digitais e as ferramentas de modelagem tridimensional e integrada.

Porém, há de se observar que essas medidas ainda são uma realidade distante dos trabalhadores informais, que ainda são os mais afetados pela pandemia. Para eles, é recomendado o uso de plataformas digitais para gerar maior proximidade com os clientes e divulgar o seu trabalho.

A crise causada pela pandemia pode representar uma oportunidade do desenvolvimento da criatividade e aplicação efetiva de métodos de otimização dos canteiros de obras. E à medida que as atividades forem retomadas, a tendência é que o setor continue a crescer. Todavia, apenas a descoberta de uma vacina pode assegurar totalmente a saúde do trabalhador e apresentar resultados mais sólidos. 


\section{Referências Bibliográficas}

AMITRANO, Claudio; MAGALHÃES, Luís Carlos G.; SILVA, Mauro Santos. Medidas de Enfrentamento dos Efeitos Econômicos da Pandemia Covid-19: panorama internacional e análise dos casos dos Estados Unidos, Reino Unido e da Espanha. 2020. Disponível em: http://repositorio.ipea.gov. br/bitstream/11058/9978/1/td 2559.pdf. Acesso em: 01 dez. 2020.

BOSQUEROLLI, Arthur Martins et al. Brasil e o Mundo Diante da Covid-19 e da Crise Econômica. 2020. Disponível em: https://www.ufpr.br/portalufpr/ wp-content/uploads/2020/07/Brasil-e-o-mundo-diante-da-Covid-19-e-dacrise-economica.pdf. Acesso em: 01 dez. 2020.

BRASIL. MINISTÉRIO DA ECONOMIA. Nota Informativa: impactos econômicos da covid-19. impactos econômicos da COVID-19. 2020d. Disponível em: https://www.gov.br/economia/pt-br/centrais-de-conteudo/ publicacoes/notas-informativas/2020/nota-impactos-economicos-da-covid19.pdf. Acesso em: 01 dez. 2020.

BRASIL. MINISTÉRIO DA SAÚDE. Coronavírus - COVID-19: diretrizes para diagnóstico e tratamento da Covid-19. 2020a. Disponível em: file://C:/ Users/Usuario/Desktop/Jeniffer/TCC\%20-\%20Let \%C3\%ADcia/O $\% 20$ V\%C3\%8DRUS\%20DA\%20COVID-19/ddt-covid-19-200407.pdf. Acesso em: 01 dez. 2020.

BRASIL. MINISTÉRIO DA SAÚDE. Painel Coronavírus. 2020c. Disponível em: https://covid.saude.gov.br/. Acesso em: 01 dez. 2020.

BRASIL. MINISTÉRIO DA SAÚDE. Protocolo de Tratamento do Novo Coranavírus: 2019-nCoV. 2020b. Disponível em: https://portalarquivos2. saude.gov.br/images/pdf/2020/fevereiro/05/Protocolo-de-manejo-clinicopara-o-novo-coronavirus-2019-ncov.pdf. Acesso em: 01 dez. 2020.

BRASIL AO CUBO. Pandemia vs Construção Civil: como podemos ser ágeis em tempos de crise? 2020a. Disponível em: https://brasilaocubo.com/ blog/pandemia-vs-construcao-civil/. Acesso em: 01 dez. 2020.

BRASIL AO CUBO. Hospital em Tempo Recorde: todos juntos no combate ao covid-19. 2020b. Disponível em: https://brasilaocubo.com/blog/ coronavirus-hospital-em-tempo-recorde/. Acesso em: 01 dez. 2020.

CÂMARA BRASILEIRA DA INDÚSTRIA DA CONSTRUÇ̃̃O. Impacto da pandemia na construção civil é maior em mercado informal. 2020a. Disponível em: https://cbic.org.br/impacto-da-pandemia-na-construcaocivil-e-maior-em-mercado-informal/. Acesso em: 01 dez. 2020.

CÂMARA BRASILEIRA DA INDÚSTRIA DA CONSTRUÇÃO. Coronavírus. 2020b. Disponível em: https://cbic.org.br/wp-content/ uploads/2020/03/coronavirus.pdf. Acesso em: 01 dez. 2020.

CARVALHO, Ricardo Tadeu de; NINOMIYA, Vitor Yukio; SHIOMATSU, Gabriella Yuka. Entenda a Importância do Distanciamento Social. 2020. Disponívelem:http://coronavirus.saude.mg.gov.br/blog/108-distanciamentosocial. Acesso em: 01 dez. 2020.

CONFEDERAC̄̃O NACIONAL DE SERVICOS. A Pandemia do Covid19 e seus Impactos na Economia Mundial Brasileira. 2020. Disponível em: http://www.cnservicos.org.br/wp-content/uploads/2020/03/Impactoseconomicos-do-Covid-19-v11.pdf. Acesso em: 01 dez. 2020.

FONTES, Giulia. Na crise, construção sofreu menos do que esperava. Mas "ressaca" da economia preocupa o setor. 2020. Disponível em: https://www. gazetadopovo.com.br/economia/retratos-da-economia-construcao-civil/. Acesso em: 01 dez. 2020.

FUNDAÇÃO OSWALDO CRUZ. Módulo 1: introdução ao novo coronavírus. introdução ao novo coronavírus. 2020. Disponível em: https:// mooc.campusvirtual.fiocruz.br/rea/coronavirus/modulo1/aula2.html. Acesso em: 01 dez. 2020.

G1 VALE DO PARAÍBA E REGIÃO. Hospital de retaguarda começa a funcionar em São José dos Campos. 2020. Disponível em: https://g1.globo. $\mathrm{com} /$ sp/vale-do-paraiba-regiao/noticia/2020/07/08/hospital-de-retaguardacomeca-a-funcionar-em-sao-jose-dos-campos.ghtml. Acesso em: $01 \mathrm{dez}$. 2020 .

INTERNACIONAL DE TRABALHADORES DA CONSTRUÇÃO E DA MADEIRA. Impactos da Covid-19 na Indústria da Construção: recomendações de políticas de saúde e segurança no trabalho para prevenção e controle da doença no setor. 2020. Disponível em: http://library.fes.de/pdf- files/bueros/brasilien/16477.pdf. Acesso em: 01 dez. 2020.

MARTINS, Matheus Alves. O Impacto da Pandemia na Construção Civil: como o setor recupera o crescimento. 2020. Disponível em: https:// engenharia360.com/pandemia-construcao-civil/. Acesso em: 01 dez. 2020.

MCINTOSH, Kenneth. Doença de coronavírus 2019: COVID-19. 2020. Disponível em: http://www2.ebserh.gov.br/documents/1688403/5111980/4. pdf/49227786-d768-470e-9ea2-7e021aa96cc9. Acesso em: 01 dez. 2020.

ORGANIZAÇÃO MUNDIAL DA SAÚDE. WHO Coronavirus Disease (COVID-19) Dashboard. 2020. Disponível em: https://covid19.who.int/. Acesso em: $01 \mathrm{dez} .2020$.

ORGANIZAÇÃO PAN-AMERICANA DA SAÚDE. Folha Informativa Covid-19: escritório da OPAS e da OMS no Brasil. 2020. Disponível em: https://www.paho.org/pt/covid19. Acesso em: 01 dez. 2020.

RODRIGUES, Lucas. Impactos econômicos da COVID-19: análise macroeconômica e setorial para o Brasil. 2020. Disponível em: https:// acoescovid19.unifesspa.edu.br/images/Impactos_econ $\% \mathrm{C} 3 \% \mathrm{~B} 4 \mathrm{micos}$ _da COVID___10_07.pdf. Acesso em: 01 dez. 2020.

SÁFADI, Marco Aurélio Palazzi. Novo Coronavírus: COVID-19. 2020. Departamento Científico de Infectologia da Sociedade Brasileira de Pediatria. Disponível em: https://www.sbp.com.br/fileadmin/user_upload/22340dDocCientifico_-_Novo_coronavirus.pdf. Acesso em: 01 dez. 2020.

SERVIÇO BRASILEIRO DE APOIO ÀS MICRO E PEQUENAS EMPRESAS. Guia Prático para a Construção Civil em Tempos de Covid-19. 2020a. Disponível em: https:/www.sebrae.com.br/sites/PortalSebrae/ufs/pe/ artigos/guia-pratico-para-a-construcao-civil-em-tempos-de-covid-19,1b990 a92bcf91710VgnVCM1000004c00210aRCRD. Acesso em: 01 dez. 2020.

SERVIÇO BRASILEIRO DE APOIO ÀS MICRO E PEQUENAS EMPRESAS. Coronavírus: confira dicas para diminuir os impactos causados pela pandemia nas empresas de construção civil. 2020b. Disponível em: https://atendimento.sebraemg.com.br/biblioteca-digital/content/dicas-parao-setor-de-construcao-civil-em-tempos-de-coronavirus. Acesso em: $01 \mathrm{dez}$. 2020.

SILVA, Mygre Lopes da; SILVA, Rodrigo Abbade da. Economia Brasileira Pré, Durante e Pós-Pandemia do COVID-19: impactos e reflexões. impactos e reflexões. 2020. Disponível em: https://www.ufsm.br/app/uploads/ sites/820/2020/06/Textos-para-Discuss\%C3\%A3o-07-Economia-BrasileiraPr\%C3\%A9-Durante-e-P\%C3\%B3s-Pandemia.pdf. Acesso em: 01 dez. 2020. 